$\pm N / E$

Global Journals Inc

is

\title{
Economic, Technical and Environmental Aspects of Recycling Lithium Batteries: A Literature Review
}

\section{By Giovanni Filomeno \& Stefano Feraco}

Ruhr-University of Bochum

Abstract- In the last few years, the automotive industry has been moving towards fuel-free and economically sustainable alternatives, motivated by the latest trends in the market and new regulations about $\mathrm{CO}_{2}$ emissions. Hybrid and electric vehicles feature a transmission drive with one or more electrical motors powered by Lithium batteries. Thus, Lithium batteries are increasingly used in onboard energy storage systems, leading new economical, technical and environmental challenges which are of fundamental importance in this early stage for the next automotive generation. Recycling materials from used Lithium batteries can also moderate the price of virgin materials, by reducing the price disposal as well as the dependence of manufacturers on exporting countries. Furthermore, recycling Lithium-ion batteries has significant environmental benefits, such as containing the risk of chemical pollution and improving safety in storage facilities for exhausted batteries worldwide. This paper aims to provide a comprehensive insight on Lithium-ion battery recycling for scientific research and industrial applications, examining the economic, technical and environmental aspects of this topic.

Index Terms: automotive engineering; battery recycling; electric vehicle; energy storage; lithiumion batteries.

GJRE-B Classification: FOR Code: 290401

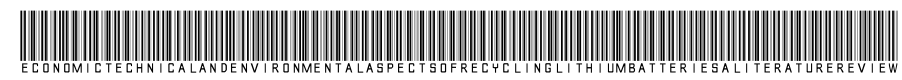

Strictly as per the compliance and regulations of:

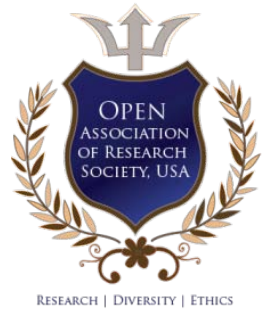

(c) 2020. Giovanni Filomeno \& Stefano Feraco. This is a research/review paper, distributed under the terms of the Creative Commons Attribution-Noncommercial 3.0 Unported License http://creativecommons.org/licenses/by-nc/3.0/), permitting all noncommercial use, distribution, and reproduction in any medium, provided the original work is properly cited. 


\title{
Economic, Technical and Environmental Aspects of Recycling Lithium Batteries: A Literature Review
}

\author{
Giovanni Filomeno $^{\alpha} \&$ Stefano Feraco $^{\sigma}$
}

\begin{abstract}
In the last few years, the automotive industry has been moving towards fuel-free and economically sustainable alternatives, motivated by the latest trends in the market and new regulations about $\mathrm{CO}_{2}$ emissions. Hybrid and electric vehicles feature a transmission drive with one or more electrical motors powered by Lithium batteries. Thus, Lithium batteries are increasingly used in onboard energy storage systems, leading new economical, technical and environmental challenges which are of fundamental importance in this early stage for the next automotive generation. Recycling materials from used Lithium batteries can also moderate the price of virgin materials, by reducing the price disposal as well as the dependence of manufacturers on exporting countries. Furthermore, recycling Lithium-ion batteries has significant environmental benefits, such as containing the risk of chemical pollution and improving safety in storage facilities for exhausted batteries worldwide. This paper aims to provide a comprehensive insight on Lithium-ion battery recycling for scientific research and industrial applications, examining the economic, technical and environmental aspects of this topic.
\end{abstract}

Index Terms: automotive engineering; battery recycling; electric vehicle; energy storage; lithium-ion batteries.

\section{InTRODUCTION}

S ince their market entry in the early 1990s, Lithiumion batteries have become an increasingly important energy storage technology since they feature a very high energy density with respect to other systems. Therefore, they have been widely used in laptops, mobile phones and portable devices [1]. Although Lithium-ion batteries have already been the dominant power source in mobile systems during the past decades, they are experiencing an ever increasing global usage in the automotive industry during the last years to face the recent trends for electric mobility [2]. Moreover, this technology is used as a buffer energy supply to account for the intermittent energy supply from renewable resources in order to match energy supply and demand [2]. Consequently, the public interest in

Author a: Industrial and Automotive Drive trains, Ruhr-University of Bochum, Germany. Advanced Development Transmission and Power train Simulation, BMW-Group, Munich, Germany.

e-mails: giovanni.filomeno@ruhr-uni-bochum.de,

giovanni.filomeno@bmw.de

Author o: LIM Mechatronics Laboratory, Politecnico di Torino, Torino, Italy.e-mail: stefano.feraco@polito.it
Lithium-ion batteries is growing steadily worldwide [3]. In this framework, electric vehicles featuring one or more electric motors using electricity stored in a Lithium-ion battery are one of the key technologies for the next generation of road transportation, along with novel algorithms for the battery State of Charge (SOC) and State of Health (SOH) monitoring and estimation [4], [5]. However, a wide range of raw materials and industrial processes is required for the manufacturing of Lithiumion batteries, resulting in supply risks, and a high economic importance of the production chain [6]. Nowadays, the production of raw materials for Lithiumion batteries is limited to a few regions around the world. This could potentially create availability and price issues [7]. The key materials that have high economic importance but also a high supply-risk are named Critical Raw Materials (CRMs). CRMs include Cobalt (Co), Manganese (Mn), Nickel (Ni), and natural Graphite. Although Lithium (Li) is not currently on the CRM list, its steadily increasing demand could result in supply issues in the very near future [8]. Lithium has a wide range of uses. In 2017, batteries counted on almost half of its use (46\%), followed by ceramics and glass (27\%), lubricating greases (7\%), polymer production (5\%), continuous casting mold flux powders (4\%), air treatment (2\%) and other uses (9\%) [8], [9]. Other materials, such as Aluminium and Copper, are also essential in terms of their contribution to the lifecycle environmental impacts of automotive batteries [8]. Therefore, the increasing demand for batteries for electric vehicles and large storage systems may put pressure on the market if combined with sudden changes in the prices of these materials. Potentially this could lead to an interruption of the manufacturing plans for electric vehicles production [7]. Consequently, recycling Lithium-ion batteries to recover useful metals was subjected to European goals from the European Union [10]. Although spent Lithium-ion batteries might be classified as non-environmentally hazardous wastes unlike other batteries containing Cadmium (Cd), Lead $(\mathrm{Pb})$ or Mercury $(\mathrm{Hg})$, the presence of flammable and toxic elements makes their safe disposal a severe issue [11].

Moreover, the N-Methyl-2-pyrrolidone (NMP) commonly used as a solvent for the fabrication of active electrode materials (cathode and anode) has been 
classified as toxic. Therefore this is potentially negative for the environment, causing human exposure to environmental hazards [11]-[13]. Hence, the technical processes of recycling Lithium-ion batteries are of immense importance for waste management sustainability. To this end, both physical and chemical processes are employed in the industry for recycling spent Lithium-ion batteries [11]. Nevertheless, there have not been firm regulations worldwide regarding the recycling of large format Li-ion batteries until now [14]. This might be fine for recyclers, who would initially face no restrictions in process design. However, restrictive regulations could be imposed afterwards. Thus, the recycling processes catered for a specific model or chemistry could become irrelevant in a few years, due to imposed restrictions [14]. The average lifespan of automotive Lithium-ion batteries is usually equal to 3-10 years. After the usage, a large amount of exhausted batteries enters the waste stream period. China, one of the leading countries in the production of Lithium-ion batteries, alone had over 500,000 tons in 2020[15]. As a matter of fact, recycling Lithium-ion batteries reduce energy consumption, as well as it results in 51.3\% natural resource savings when compared to landfill [16][18]. Furthermore, the main benefit of recycling Lithiumion batteries lies in avoiding virgin materials extraction from developing countries [16], [19]. However, it is not possible to recycle Lithium-ion batteries without causing any environmental consequences. Thus, a solid discussion on the ecological impact of Lithium-ion batteries recycling processes is still under ongoing research [16], [20].

Considering the framework mentioned above, this paper aims to provide a literature review about the disposal methods and the global impact of recycling a large number of Lithium-ion batteries for electric vehicles that will enter the market in the coming years and will reach the End-of-Life (EOL) in the next decades. Furthermore, the paper focuses on a comprehensive insight into the several perspectives of recycling postmortem Lithium-ion batteries since the topic needs a multidisciplinary approach, illustrating risks and benefits of Lithium-ion batteries manufacturing and recycling. To that end, Section 2 explains the economic, technical and environmental backgrounds organized in subsections, respectively.

\section{Aspects of Recrcling Lithium- IONBATTERIES}

\section{a) Economic Aspects}

Cost savings from battery recycling could be in a range of $43 \%$ to $90 \%$ when compared with a battery entirely made of virgin materials [7][21]. The main elements in a battery (Cobalt, Lithium, Copper, Graphite, Nickel, Aluminium and Manganese) are reported to comprise over $90 \%$ of the economic value of a spent
Lithium-ion battery: Cobalt (39\%), Lithium (16\%), Copper (12\%), Graphite (10\%), Nickel (9\%), Aluminium (5\%) and Manganese (2\%) [21] [22]. These premises lead to the proposal of a circular green economy for Lithium-ion batteries [8], [23], even imposing mandatory recycling rates in the manufacturing process [24].

One of the most critical aspects of the increased demand for batteries can be seen in the price of Cobalt. It rose from 20,000 \$/ton in 2001 to 80,000 $\$ /$ ton in 2017 with an average increase in demand of around 3\% per year [25]. After the political situation in Congo was stabilized resulting in a decline of interest from financial speculators, the price fell, and today it is around 29,000 \$/ton. Congo has the largest Cobalt mining reserves in the world (3.6 million metric tons in 2019), yet its political situation causes internal conflicts, illegal mining, human rights abuses, and harmful environmental practices.

The same behaviour can be observed for Aluminium. Its price grew from 1,500 \$/ton in 2015 to $2,500 \$ /$ ton in 2018. After this peak, the price went down to $1,800 \$ /$ ton at the end of 2019. Nickel is an exceptional case. Its cost decreased from 29,000 \$/ton in 2011 to $7,700 \$$ /ton in 2016. From 2016 to the end of 2019 , the price increased up to $18,000 \$ / \operatorname{ton}[26]$. Its peak was 50,000 \$/ton in 2006 . It is reasonable to believe that with increasing demand, its price will increase as it has happened with other materials.

The Lithium price has largely increased between 2016 and 2018[21], going from 80,000 \$/ton to 170,000 $\$ /$ ton. Today however, its cost has drastically decreased, discouraging its recycling [27]. It has even decreased by $14 \%$ since the beginning of 2019due to changing global trading contract.

Regarding graphite, its price has doubled from 2007 to today, going from approximately1000 \$/ton to 2500 \$/ton.

An even higher increase can be observed for Manganese, its price increasing from $2 \$$ per Dry Metric Ton Unit (dmtu) to $6.2 \$ / \mathrm{dmtu}$ with a peak of $8 \$ / \mathrm{dmtuin}$ 2016 and 2018.

Due to these huge fluctuations in the price of the main components used in battery manufacturing and recycling, the economy related to Lithium-ion batteries might be influenced by both positive and negative aspects. Suffering from wide fluctuations, as in the case of Cobalt, it may not be economically sustainable to recycle the material compared to producing it newly from the mines. The economic possibility will, therefore, be strongly linked to the development of techniques that make recycling more convenient than manufacturing and assembling a new product from virgin material extracted from the Earth's crust. Furthermore, another crucial factor that must be considered for long-term investment is understanding how the automotive market will move. It cannot be excluded, for example, that a different type of battery, 
such as Lithium-air (Li-air), will enter the market soon or that a different type of propulsion, such as Hydrogenbased power units, will dominate the automotive market in the near future, thus making battery recycling not convenient [28].

\section{b) Technical aspects}

The recycling of automotive Lithium-ion batteries to supply production is a long-term strategy which has technical limits. Batteries are expected to have a lifespan of 10 years for propulsion and eventually of 5 to 10 years in a second-life application (i.e. utility) [29]. This means that the set of recycled batteries will not be available before 10-20 years after the massmarket diffusion of electric vehicles. The cooling system plays a fundamental role in the performance and the life of a battery [30] as well as in the performance of the electrical and electronics components [31], [32] which in turn have an influence on the battery life [33]. Furthermore, accurate systems for the estimation of the $\mathrm{SOC}$ and $\mathrm{SOH}$ could prolong the life of Lithium-ion batteries by avoiding deep discharge and charge cycles at extremely high or cold temperatures, which are one of the major factors that shorten the life of a battery [4],[5]. The efficiency of the battery depends on the collection rate and recycling efficiency. The collection rate is defined as the fraction of collected batteries at their EOL over the total produced Lithium-ion batteries. The recycling efficiency is the ratio of metals and metal components which are recovered from batteries that have reached the EOL [34]. The main constitutive components are listed in Table I [35]. From Table I, it is clear that the production of the cathode, anode and electrode has the central importance in terms of manufacturing processes, but the production of the battery case using plastic materials also has a significant impact. The complete set of materials used in the production of electric vehicle batteries is usually not available from a single manufacturer. A raw composition can be found in literature and is presented in Table ॥ [36] for a Nickel Manganese Cobalt Oxide (NMC) battery and a Lithium Iron Phosphate (LFP) battery.

Table 1: Components of Lithium Battery [30]

\begin{tabular}{|c|c|}
\hline Components & Amount (weight \%) \\
\hline $\begin{array}{c}\text { Cathode, Anode and } \\
\text { Electrode }\end{array}$ & $40 \pm 1.5$ \\
\hline Plastic case & $22 \pm 1$ \\
\hline Steel case & $11 \pm 1.5$ \\
\hline Copper Foil & $9 \pm 0.5$ \\
\hline Aluminium Foil & $6.5 \pm 0.5$ \\
\hline Electrolyte & $5 \pm 1$ \\
\hline Solvent & $5.5 \pm 1$ \\
\hline Electrical board and circuit & $1.5 \pm 0.5$ \\
\hline
\end{tabular}

Table 2: Materials of Lithium Battery [36]

\begin{tabular}{|c|c|c|c|}
\hline \multicolumn{2}{|c|}{ NMC battery } & \multicolumn{2}{c|}{ LFP battery } \\
\hline Lithium & $117 \mathrm{~g}$ & Lithium & $119 \mathrm{~g}$ \\
\hline Nickel & $459 \mathrm{~g}$ & Iron & $1030 \mathrm{~g}$ \\
\hline Manganese & $432 \mathrm{~g}$ & Phosphorous & $478 \mathrm{~g}$ \\
\hline Cobalt & $467 \mathrm{~g}$ & Graphite & $1,560 \mathrm{~g}$ \\
\hline Graphite & $1,626 \mathrm{~g}$ & & \\
\hline
\end{tabular}

The main components of a Lithium-ion battery are analyzed in the following.

i. Cobalt

The Cobalt contained in the battery cathodes is mainly produced in the Democratic Republic of the Congo (DRC), which supplies $51 \%$ of the global cobalt production. The political instability of the region and the strong dependence on this material is currently a severe issue its market price.

Cobalt has an underestimated recycling rate of 16\% [37]. Until 2020, the production was able to supply the demand without experiencing difficulties [38]. However, predictions for up to 2050 show that the supply of all existing resources, even at a high recycling rate, will not be enough for the cumulative demand [36]. This requires the market to find new solutions or alternatives.

ii. Nickel

Nickel is produced in the Philippines, Russia, Canada and Australia. It is used in high quantity in the cathodes. For instance, it represents $80 \%$ of the cathode composition of Tesla vehicles, and the penetration of the electric vehicle in the market of the near future will almost certainly influence the actual price [39]. If electric vehicles are to account for $10 \%$ of the global car fleet, the production of Nickel will surely reach 400,000 tons per year [26].

\section{iii. Aluminium}

Aluminium is used in several parts of electric vehicles such as the car body, battery casing and brake components. It is commercialized in different forms: primary, downstream and secondary Aluminium. The production of the primary Aluminium emits more emissions than secondary (recycled) production. Remolding Aluminium requires only 5\% of new production, and this leads to a clear climate benefit [40].Recycling is therefore encouraged by environmental and economic factors, above all for tense relations between China, the world's leading producer, and the West.

\section{iv. Lithium}

Lithium is the 27th most present element in the lithosphere [34]. As a matter of fact, the estimations on the total quantity of Lithium present in the Earth show 45.2 million tons, and from 12.2 to 14 million tons for global resources and reserves, respectively [36][41]. 
Lithium is found in different mineral forms and compounds which vary according to the percentage of the element contained. For this reason, the amount of Lithium is evaluated in terms of Lithium metal-equivalent, which represents the amount of element contained in the mineral or compounds.

Lithium resources are mostly located in South America (55\%), Asia (17\%) and North America (13\%). The lithium reserves are located in South America (69\%), Asia (17\%) and North America (7\%) [34]. In South America, the major producers are Argentina, Chile, Bolivia and Brazil. On the other side, China is the principal supplier in Asia, with $12 \%$ of the global resources and $17 \%$ of the global reserves [6].

More than half of the production in North America is provided by the USA, which has the $8 \%$ and $5 \%$ of the global resources and reserves respectively [34].

Predictions show that even with the increase of the demand of the electric vehicle, the production rate of Lithium will still be enough until 2050without recycling it. Today, the recycling of Lithium is technically feasible, but the cost is still relatively high. However, the longterm lithium price or political and social changes could force the development of new practices which decrease the costs and make Lithium recycling more feasible [36].

\section{v. Natural graphite}

Graphite is a common material used for the anode in many battery technologies. It is composed by sheets of carbon atoms which lead to an electrical conducting material. Two types of graphite can be used for this purpose: they are synthetic and natural graphite, which have different price and characteristics.

The synthetic graphite comes from petrochemical processing [42], and it has a pure carbon structure. It leads to high performance, but it is expensive in terms of energy consumptions and costs, which are between 7000 and 20000 \$/tons [43]. For this reason, a cheaper alternative has been found in the natural graphite, which has a cost between 6000 and 10000 \$/tons for the version with 90-95\% of carbon [44]. Most of the reserves are located in Asia, especially in China and India, which have up to $85 \%$ of the global resources [45],[46]. The annual production is estimated around 1.6 million tons and $4 \%$ is used for batteries [47].

\section{vi. Manganese}

As with Lithium, the Manganese is largely found in the Earth's crust, and its abundance is around $0.1 \%$. The production is around 16 million tons, and it is used for iron and steel manufacturing [36],[43]. The recycling of this material is particularly difficult due to the chemical treatments to be carried out. For this reason, recovery is not yet very developed in Europe, except Germany, and is instead practiced in China, Korea and the Philippines.

\section{vii. Phosphorous}

Phosphorous has the same abundance of Manganese in the Earth's crust. The phosphate rocks, also called Phosphorite, are estimated around 67 billion tons and 300 billion tons in global reserves and resources, respectively [36]. From this rock, via a reduction chemical process, the metallic phosphorous can be produced. The price for phosphate rock is 3740 \$/tons [43].

Considering the complete process of recycling materials from a Lithium-ion battery, it should include a combination of unit operations, in which Lithium and other materials are eventually recovered. Whatever the actual process path in the recycling industry is, it will always be a combination of the following fundamental operations: deactivation, thermal and/or mechanical pre-treatments, hydrometallurgy and/or pyrometallurgy [48],[49]. Complete technical insight on the opportunities, issues and processes of recycling treatments for Lithium-ion batteries can be found in [11], [50], and [51].

\section{c) Environmental aspects}

The demand for Lithium has grown steadily by $6 \%$ per year in the last twenty years [52]. This growth is expected to increase in parallel with the increase in hybrid and electric cars. Considering the increase of the electric vehicles and the availability of materials, it may be noted that there could be a Lithium shortage before 2050 [53]. Nowadays, 70\% of its production is in the "ABC" area (Argentina, Bolivia and Chile). Therefore, the increase in demand will produce an expansion of the suppliers. Hence, questions will have to be asked about the environmental and social sustainability of those areas. Also, reserves of Lithium are mostly located in South America, where it can be found in the form of salt. This Lithium salt that is found in the subsoil is dissolved by using copious quantities of water, which is pumped to the surface and then divided from the salt by evaporation. This process also leads to water scarcity problems in regions that are quite poor. Lithium recycling can reduce the load for mining and avoid the emergence of environmental and social problems. Moreover, every material extracted from the Earth is a potential waste, except for metals that are potentially being recycled [54]. Waste from electronic and electrical equipment is one of the fastest-growing waste streams, thus causing an increasing need for disposal areas worldwide [16]. This carries a serious risk of increasing the number of harmful chemicals that can enter the environment [55]. Furthermore, the increasing disposal of portable batteries consisting of various toxic substances could result in disruptive effects for the environment, since their use has almost doubled in the last decade [56]. Although containing fewer quantities of toxic materials than other batteries, a thorough assessment of their recycling process is needed after 
disposal [17]. The reason for this is that recycling Lithium-ion batteries leads to a reduction of energy consumption, greenhouse gas emissions and natural resource savings with respect to landfill [17][16][18]. Furthermore, avoiding virgin materials production has major benefits for the environment. However, production and recycling of lithium-ion batteries cannot be performed without causing any environmental impacts, as for the high amount of production stages mostly linked with metalworking [19][20].

The Lithium-ion battery production can be mainly divided in the production of the anode, the cathode and the battery pack, because the separator, Lithium salts and solvents have a marginal impact [57]. The battery pack also contains cables and the printed wiring board, which could cause up to $20 \%$ of the possible impact on the environment [57]. Copper in the anode is needed as collector foil, and it contributes strongly to the environmental burden of a Lithium-ion battery [57]. Additionally, Copper is also used in the wiring system. Graphite and all other components of the anode only have a marginal impact. The cathode's collector is made of Aluminum foil, and it has an even higher environmental burden in the cathode production chain [57]. The printed wiring board, the process heating and Nitrogen are also important contributors to the total impact of a Lithium-ion battery production, along with the Copper and Aluminum collector foils, Graphite and active materials [57]. Furthermore, the mining and manufacturing processes related to the production of automotive batteries create the largest environmental impact, since the valuable anode and cathode metals can be recycled up to $25 \%$, while total amount of metals recycled is over $47 \%$ [35].

Considering the metalworking related to automotive batteries, Chromium and Zinc chemicals, for instance, are used for protective metal plating. However, Zinc is normally contaminated by Cadmium, while Copper mining and smelting are strongly linked with the use of Arsenic, which is both toxic and dissipative, as well as Cadmium which can be found near Zinc refineries. Fortunately, Steel and its alloys, Aluminum and Copper are quite easy to recycle, with a recycling rate up to $45 \%$ in the U.S.A.[54]. Nevertheless, many compounds of various metals, such as Arsenic, Cadmium, Copper, Zinc, Lead, Nickel, Chromium, Manganese, Cobalt, Vanadium, Selenium, Tin and Mercury, are toxic to plants and animals. Moreover, salts of Copper, Zinc, Chromium, Tin, Bismuth and Thallium are also toxic to the whole ecosystem. Although many of these metals are recovered for other commercial products, others are almost entirely dissipated or discarded after use [54]. Another point is that the production plants have a major impact on environmental pollution, especially in facilities where environmental controls are weak, as in developing countries. These facilities emit significant amounts of particulates, carbon monoxide, benzene and other aromatics, ammonia and hydrogen sulfide [54]. Aluminium production is performed by means of a polluting process consuming a large amount of lime and caustic soda, generating a caustic waste called "red mud" which is usually left in ponds near the alumina plant. Red mud contains iron. This is useless and corrosive, and it can pollute groundwater, especially in wet climates. Aluminium smelting needs to be performed in remote places mainly to exploit cheap electric power and to minimize the exposure of local populations to fluoride pollution. Electroplating industry also uses toxic heavy metals, such as Chromium and Cadmium, which can end up in the aquifers [54]. Moreover, the rapid growth of this kind of manufacturing in Asia and South America will increase pollution from these sources, which is completely inconsistent with long-term ecological sustainability. For these reasons, it is of fundamental importance to list a serious assessment of environmental impacts of Lithium-ion batteries, imposing the need of closing the materials cycle from extraction to disposal [54] and adopting a green circular economy [58][50]. This fact is crucial for limiting the impact not only of the toxic and non-ferrous metals linked with batteries production, such as Lithium, Cobalt Cadmium, Copper, Mercury, Silver and Zinc, but also ferrous metals, like Chromium and Nickel. Unfortunately, non-ferrous metals are often dispersed in the environment at very low concentrations that make recycling impracticable in most cases.

Furthermore, in the next few years, a huge amount of wasted automotive Lithium-ion batteries will be sent to recycling facilities, introducing novel issues in terms of chemical and industrial safety. Lithium-ion batteries will also require an efficient and safe dismantling phase before treatments, in order to transform current manual procedures in fast, automated systems [59], [50]. Also, several legislations aimed at the management of wasted automotive Lithium-ion batteries will be needed, but there are still some limitations for the industrial treatment due to lack of data sharing, the uncertainty on responsibilities and the unrealistic targets for collection and recycling [50].

\section{ili. Conclusion}

The rapid growth of electric vehicles will increase the demand on critical materials such as Cobalt, Lithium and Graphite. The consequent growth in demand could lead to potential price increment, with economic consequences which must be strongly assessed. Moreover, the application of Lithium-ion batteries in automotive industry has been growing steadily in the last decade and processes related to Lithium-ion batteries will constitute one of the most important industries in the following years. Nowadays, recycling wasted Lithium-ion batteries is a crucial issue 
to consider, along with improving manufacturing processes, in order to reduce pollution and protect the environment. Moreover, it is fundamental to improve mining and extraction processes both for saving the Earth from global pollution and for reducing hazards for humans. This could be achieved by recycling spent Lithium-ion batteries, and hence minimizing the extraction of raw material from the soil. Therefore, recycling processes should guarantee high recovery efficiency at the lowest environmental impact, allowing primary raw material savings, economic gains, energy consumption reduction, waste minimization and safe management of harmful components. This paper has presented an insight on Lithium-ion battery recycling for scientific research and industrial applications, examining the economic, technical and environmental perspectives of this vast topic.

\section{Conflict of Interest}

The authors declare no conflict of interest.

\section{Author Contributions}

Giovanni Filomeno conceived the paper and its sections. Stefano Feraco provided most of the literature. All authors wrote the paper and approved the final version.

\section{References Références Referencias}

1. H. E. Melin, C. E. Storage und G. Ledung, "State-ofthe-art in reuse and recycling of lithium-ion batteries-A research review", Swedish Energy Agency, 2019.

2. D. Deng, "Li-ion batteries: basics, progress, and challenges", Energy Sci. Eng, 3(5), 385-418., 2015.

3. S. Levine, "The Great Battery Race", Foreign Policy 182:88-95, 2010.

4. A. Bonfitto, E. Ezemobi, N. Amati, S. Feraco, A. Tonoli und S. Hegde, "State of Health Estimation of Lithium Batteries for Automotive Applications with Artificial Neural Networks", 2019: AEIT International Conference of Electrical and Electronic Technologies for Automotive (AEIT AUTOMOTIVE) (pp. 1-5). IEEE.

5. A. Bonfitto, S. Feraco, A. Tonoli, N. Amati und F. Monti, "Estimation Accuracy and Computational Cost Analysis of Artificial Neural Networks for State of Charge Estimation in Lithium Batteries", Batteries, 5(2), 47., 2019.

6. N. Lebedeva, F. Di Persio und L. Boon-Brett, "Lithium-ion battery value chain and related opportunities for Europe", Petten: European Commission, 2016.

7. D. M. Steward, A. T. Mayyas und M. K. Mann, "Economics and Challenges of Li-Ion Battery Recycling from End-of-Life Vehicles", Procedia Manufacturing, 33(NREL/JA-6A20-71350)., 2019.

8. N. Hill, D. Clarke, L. Blair und H. Manadue, "Circular Economy Perspectives for the Management of
Batteries used in Electric Vehicles", European Commission, 2019.

9. Lithium. Retrieved from U.S. Geological Survey (USGS), Available from: https://minerals.usgs.gov/ minerals/pubs/commodity/lithium/, 2018.

10. "End-of-life vehicles - reuse, recycling and recovery", totals, Euro Stat: http://ec.europa. eu/eurostat/cache/metadata/en/env_waselvt_esms. $\mathrm{htm}$.

11. O. E. Bankole, C. Gong und L. Lei, "Battery recycling technologies: recycling wastelithium ion batteries with the impact on the environment inview", J. Environment Ecology, 4, 14-28, 2013.

12. S. Castillo, F. Ansart, C. Laberty-Robert und J. Portal, "Advances in the recovering of spent lithium battery compounds", Journal of Power Sources, 112, 247-254., 2002

13. E. P. Roth und C. J. Orendorff, "How electrolytes influence battery safety", The Electrochemical Society Interface. pp 45-49., 2012.

14. L. Gaines, "The future of automotive lithium-ion battery recycling: Charting a sustainable course", Sustainable Materials and Technologies, 1, 2-7., 2014.

15. W. Zhang, C. Xu, W. He, G. Li und J. Huang, "A review on management of spent lithium ion batteries and strategy for resource recycling of all components from them", Waste Management \& Research, 36(2), 99-112., 2018.

16. A. Boyden, V. K. Soo und M. Doolan, "The environmental impacts of recycling portable lithiumion batteries", Procedia CIRP, 48, 188-193., 2016.

17. L. Gaines, J. L. Sullivan, A. J. Burnham und I. Belharouak, "Life-Cycle Analysis for Lithium-Ion Battery Production and Recycling", 90th Annual Meeting of the Transportation Research Board, Washington, 2011.

18. J. Dewulf, G. Van der Vorst, K. Denturck, H. Van Langenhove, W. Ghyoot, J. Tytgat und K. Vandeputte, "Recycling rechargeable lithium-ion batteries: Critical analysis of natural resource savings", Resour. Conserv. Recycl., vol. 54, no. 4, pp. 229-234, Feb. 2010, 2010.

19. K. Fisher, E. Wallen, P. P. Laenen und M. Collins, "Battery Waste Management Life Cycle Assessment", European Portable Battery Association, 2006.

20. R. Hischier, P. Wäger und J. Gauglhofer, "Does WEEE recycling make sense from an environmental perspective?: The environmental impacts of the Swiss take-back and recycling systems for waste electrical and electronic equipment (WEEE)", Environ. Impact Assess. Rev., vol. 25, no. 5, pp. 525-539, Jul.

21. M. Pagliaro und F. Meneguzzo, "Lithium battery reusing and recycling: A circular economy insight", Heliyon, 5(6), e01866., 2019. 
22. A. Kochbar und T. G. Johnston, "A Process, Apparatus, and System for Recovering Materials from Batteries", Patent Scope, App. No. PCT/CA2018/050640, WO2018218358A1, 2018.

23. H. Idjis, D. Attias, J. C. Bocquet und S. Richet, "Designing a sustainable recycling network for batteries from electric vehicles. Development and optimization of scenarios", In Working Conference on Virtual Enterprises (pp. 609-618),Springer, Berlin, Heidelberg, 2013.

24. C. Hoyer, K. Kieckhäfer und T. S. Spengler, "Impact of mandatory rates on the recycling of lithium-ion batteries from electric vehicles in Germany", In Reengineering Manufacturing for Sustainability (pp. 543-548),Springer, Singapore., 2013.

25. P. Alves Dias, D. Blagoeva, C. Pavel und N. Arvanitidis, "Cobalt: demand-supply balances in the transition to electric mobility", Report E.U.R. 29381, 2018.

26. J. Desjardins, "Electric cars are going to mean a lot of demand for Nickel", UK Business Insider (https://goo. gl/7t49mV)., 2017.

27. A. Leader, G. Gaustad und C. Babbitt, "The effect of critical material prices on the competitiveness of clean energy technologies", Materials for Renewable and Sustainable Energy, 8(2), 8, 2019.

28. M. Park, H. Sun, L. H., J. Lee und J. Cho, "LithiumAir Batteries: Survey on the Current Status and Perspectives towards Automotive Applications from a Battery Industry Standpoint", Advanced Energy Materials 2(7), 2012.

29. L. Gaines, "Lithium-ion battery recycling processes: Research towards a sustainable course", Sustainable materials and technologies, 17, e00068., 2018.

30. L. H. Saw, A. A. O. Tay und L. Winston Zhang, "Thermal Management of Lithium-ion Battery Pack with Liquid Cooling", San Jose, CA: Thermal Measurement, Modeling \& Management Symposium (SEMI-THERM), 2015.

31. G. Filomeno, B. Krüger, P. Tenberge und D. Dennin, "Automatization of Pin Fin Heat Sink Design with Geometric and Fluid Constraints", International Journal of Mechanical Engineering and Robotics Research, Bd. 9, Nr. 5, pp. 652-657, April 2020.

32. S.-Z. Xu, Y.-F. Peng und S.-Y. Li, "Application Thermal Research of Forced-Air Cooling System in High-Power NPC Three-Level Inverter Based on Power Module Block", Case Studies in Thermal Engineering 8, 10.1016/j.csite.2016.10.002, 2016.

33. Z. Li, G. Lee, X. Gao, X. Zhang, Z. Gu und M. Zou, "Impact of Electromagnetic Interforance from Power Inverter Drive System on Batteries in Electric Vehicle", 1876-6102 (c) 2016 Published by Elsevier Ltd. This is an open access article under the CC BYNC-ND license (http://creativecommoApplied Energy Symposium and Summit 2015: Low carbon cities and urban energy systems, doi: 10.1016/ j.egypro.2016, 2016.

34. A. Chagnes und J. Swiatowska, "Lithium Process Chemistry. Resources, Extraction, Batteries, and Recycling", Amstedam: Elsevier, 2015.

35. A. Rahman, R. Afroz und M. Safrin, "Recycling and Disposal of Lithium Battery: Economic and Environmental Approach", 2017: IIUM Engineering Journal, 18(2), 238-252. 2017.

36. B. Reuter, J. Riedl, T. Hamacher, M. Lienkamp und A. M. Bradshaw, "Future Resource Availability for the Production of Lithium-Ion Vehicle Batteries", available from https://mediatum.ub.tum.de/doc/ 1226680/1226680.pdf., 2014.

37. On the review of the list of critical raw materials for the E.U. and the implementation of the Raw Materials Initiative, Communication from the Commission to the European Parliament, the Council, the European Economic and Social Commitee and the Committee of the Regions, 2014.

38. Report on critical raw materisl for the E.U., 2015: Ares 1819503.

39. P. Hummel, D. Lesne, J. Radlinger, C. Golbaz, C. Langan, K. Takahashi, D. Mulholland, A. Stott, G. Haire, M. Mittermaier, N. Gaudonis und L. Shaw, "UBS Evidence Lab Electric Car TeardownDisruption Ahead Report", UBS, 2017.

40. E. Drabik und V. Rizos, "Prospects for electric vehicle batteries in a circular economy", URL: https://www. ceps. eu/system/files/RR, 20., 2018.

41. U.S. Geological Survey, Minerals Information, Lithium. Statistics and Information, Mineral Commodity Summaries, Available from: http:// minerals.usgs.gov/minerals/pubs/commodity/lithium I, 2016.

42. A. Bruno, "Synthetic graphite may be purer but the future belongs to natural graphite", http:// investorintel.com/graphite-graphene-intel/syntheticgraphite-is-purer-but-the-future-belongs-to-naturalgraphite/.

43. U.S. Geological Survey, 2012 Minerals Yearbook.

44. V. Diniz, Synthethic Graphite, Canada Carbon.

45. U.S. Geological Survey, Mineral Commodity Summeries 2013.

46. T. J. Brown, R. A. Shaw, T. Bide, E. Petavratzu, E. R. Raycraft und A. S. Walters, "Wold Mineral Production 2007-11", Britisch Geological Survey, 2013.

47. "Annex $\vee$ to the Report of the Ad-hoc Working Group on defining critical raw material", European Comission, Critical raw materials for the EU, 2010.

48. J. Engel und G. Macht, "Comparison of Lithium-Ion Recycling Processes for Electric Vehicle Batteries", In Anaheim, CA: Industrial and Systems Engineering Research Conference (ISERC), 2016. 
49. M. Fleischmann, M. Krikke, H. R. Dekker und S. D. $P$. Flapper, "A characterisation of logistics networks for product recovery", Omega, 28(6), 653-666.

50. E. Mossali, N. Picone, L. Gentilini, O. Rodriguez, J. M. Pérez und M. Colledani, "Lithium-ion batteries towards circular economy: A literature review of opportunities and issues of recycling treatments", Journal of Environmental Management, 264, 110500. 2020.

51. T. Georgi-Maschler, B. Friedrich, R. Weyhe, H. Heegn und M. Rutz, "Development of a recycling process for Li-ion batteries", Journal of power sources, 207, 173-182, 2012.

52. Roskill, Lithium Global Industry, Markets and Outlook, London: Roskill Information Services, 2015.

53. L. Gaines und P. Nelson, "Lithium-ion batteries: examining material demand and recycling issues", Minerals, Metals and Materials Society, 2010.

54. R. U. Ayres, "Metals recycling: economic and environmental implications", INSEAD's Center for the Management of Environmental Resources, 21(3), 145-173., 1997.

55. H. Y. Tammemagi, "The Waste Crisis: Landfills, Incinerators, and the Search for a Sustainable Future", 1st edition. New York: Oxford University Press, 1999.

56. K. O'Farrell, R. Veit und D. A'Vard, "Trend analysis and market assessment report", National Environment Protection Council Service Corporation, Jul., 2014.

57. D. A. Notter, M. Gauch, R. Widmer, P. Wager, A. Stamp, R. Zah und H. J. Althaus, "Contribution of Liion batteries to the environmental impact of electric vehicles", Environ. Sci. Technol. 2010, 44, 17, 65506556 2010., 2010.

58. M. Bini, D. Capsoni, S. Ferrari, E. Quartarone und P. Mustarelli, "Rechargeable Lithium Batteries: Key Scientific and Technological Challenges", Rechargeable Lithium Batteries, Elsevier, 2015.

59. L. Yun, D. Linh, L. Shui, X. Peng, A. Garg, M. L. Phung, S. Asghari und J. Sandoval, "Metallurgical and mechanical methods for recycling of lithium-ion battery pack for electric vehicles", Resources, Conservation and Recycling, Volume 136, September 2018, Pages 198-208, 2018. 